\title{
THE ROLE OF GOVERNMENTS AND GREEN BUILDING COUNCILS IN CITIES' TRANSFORMATION TO BECOME SUSTAINABLE: CASE STUDIES OF HONG KONG (EAST) AND VANCOUVER (WEST)
}

\author{
AILIN IWAN \& KENNETH K.Y. POON \\ Philia Earth Limited, Hong Kong (SAR).
}

\begin{abstract}
The transformation of older cities in order to mitigate the climate change phenomenon has been a global trend, covering multiple strategies to enhance better environment for cities to become more viable places to live. Collaboration of multidisciplinary professionals, advancement of technological innovation, socio-political participation, public education, and governments' leadership is needed to enhance the quality of life of urban dwellers. In particular, government policies play critical roles to advance cities' sustainable goals. However, the role of Green Building Councils (GBCs) is undeniably critical to facilitate such changes. Two advanced sustainable cities Hong Kong (a representative city from Eastern countries) and Vancouver (a representative city from Western countries) were selected as case studies to understand the roles of the local governments and GBCs in leading cities' transformation to achieve sustainable cities goals. Related official documents such as 'Energy Saving Plan for Hong Kong's Built Environment 2015-2025+', 'Hong Kong's Climate Action Plan 2030+', and 'Greenest City 2020 Action Plan' of the City of Vancouver were analyzed to identify the governments' visions, goals, and strategies in greening their cities. A series of expert interviews were conducted to understand the direction of these institutions in driving the changes in policy and practices which included: (i) Government officials and leaders from GBCs in both cities; (ii) Leaders from World Green Building Councils; and (iii) Director of Environment and Development in United Nations Economic and Social Commission for Asia and the Pacific (UN-ESCAP). New prominent green buildings in both cities were observed during site visit to understand the manifestation of the action plan documents in the built environment field. Similarities and differences approaches of both cities to achieve sustainable statuses along with implications, recommendations, and future directions were discussed.
\end{abstract}

Keywords: cities' transformation, eco-cities, governments' policies, green-building councils, smartcities, sustainable cities.

\section{INTRODUCTION}

Urbanization is occurring at an unprecedented rate, with the projection that three-quarters of the world's population will live in urban environments by 2050 [1]. This estimation is a strong indicator that cities play critical roles not only to provide urban environmental quality for their residents at a minimum acceptable standard, but also to be resilient to complex environmental challenges such as climate change. The threat of climate change has increased the interest for research, education, policy making, and business to seriously develop further the understanding and most importantly the implementation of sustainable cities. The conceptualization of urban sustainability requires beyond sustainability goals or aspirations, but more importantly on the resilience of the urbanization process [2]. Multidisciplinary collaboration of professionals, together with socio-political participation, technological innovation, public education, and government leadership are needed to enhance the quality of life of city dwellers. Cities dealt with complex issues such as transportation, housing, water, power, food, health, waste, and so forth.

Cities' livability and the quality of life of their residents are highly depended on the goals and visions of the decision makers whose voices matter in the direction of city planning. 
Vision of the local government in cities' transformation becomes the cornerstone to drive the changes in the cities to become smart, eco-friendly, sustainable, and resilient. It is also critical to observe the roles of Green Building Councils (GBCs) in facilitating government's visions to implement the sustainable cities' goals. Having goals to transform cities to become sustainable is critical, however, it is equally important to strengthen cities' resilience in facing new challenges and in responding to sudden changes occurred in such complex network societies.

This research in particular evaluates the soft powers behind the urban transformation, namely the local governments and the GBCs. Two case studies of advanced sustainable cities: Hong Kong to represent the East and Vancouver to represent the West were selected. Hong Kong was ranked the $8^{\text {th }}$ sustainable city in the world by the global design and engineering consultant company, Arcadis, in year 2015. Vancouver was ranked the $1^{\text {st }}$ sustainable city in the world by the World Green Building Council (WGBC) the same year. The selection of these two cities are also based on their similarities in terms of their local governments' strong leadership in transforming the cities to be 'green' and their active GBCs that work closely with the governments to realize such ambitious visions. Furthermore, it is important to acknowledge that both cities have taken multiple concrete actions in mitigating climate change with the production of 'Energy Saving Plan for Hong Kong's Built Environment 2015-2025+' and 'Hong Kong's Climate Action Plan 2030+' from the City of Hong Kong, and 'Greenest City 2020 Action Plan' from the City of Vancouver.

\subsection{An Overview of Sustainable Cities}

The threat of the rapid increase of the world population led to a sense of urgency to develop new cities or to transform existing cities to become not only sustainable, but also resilient to new changes with a concrete goal that cities should provide quality spaces for urban dwellers. Sustainable urbanization represents the objective for managing the dynamics of future city development to achieve desirable environmental, social, economic, and political-institutional outcomes for the long term [3]. The concept of 'sustainable cities' was further developed through combining the area of sustainable development and urbanization, which became interest of research, education, policy making, and business which manifested in all parts of society [4]. The conceptualization of urban sustainability incorporates a complex systems perspective of urban areas and their global hinterlands, with a focus not only on sustainability goals or aspirations, but also on the resilience of the urbanization process [2,5].

Various pressures of the cities such as climate change, ageing infrastructure, ageing population, and increase consumption can be seen as slow-burn issues that occurred imperceptibly but are often ignored by short-sighted planning while it has significant cumulative impact in decades [6]. Furthermore, cities need to mitigate immediate problems such as financial crisis, earthquake, any extreme weather event, breach of biosecurity, unexpected surge in population, as well as major infrastructure disruption [7].

Upon the signing of the Paris Agreement after COP-21 took place in December 2015, global political leaders have begun to recognize the needs of strategic and immediate solutions to mitigate climate change. It is projected that many cities will experience more frequent and severe head waves in the future as well as risks of flooding and the sea-level rise [8].

There are various ways to mitigate such threat. Government leadership in this area is critical while GBCs can be seen as the linkage between the governments with professional experts in the built environment field whom many are involved in shaping the cityscape through 
innovative design and construction technology. The two case study cities in this research, Hong Kong and Vancouver, serve as models from the East and the West to showcase that they involve both active local governments and active GBCs to mobilize cities' movement to become more sustainable in facing the threat of climate change. The positive results can be justified by the increased number of new green buildings or existing buildings retrofitted that meeting the green certification schemes and also the active launching of various green campaigns.

\subsection{Energy Saving Plan for Hong Kong’s Built Environment 2015-2025+ [9]}

The following literature is extracted from the report of 'Energy Saving Plan for Hong Kong's Built Environment 2015-2025+'. Energy saving policy in Hong Kong focuses on driving energy saving through a combination of educational, social, economic, and regulatory means, especially for buildings and inhabitants to become highly energy efficient by 2025 . Hong Kong's goal is to achieve an energy intensity reduction target by $40 \%$ by 2025 using 2005 as the base. Hong Kong's strategies in energy saving and reductions are: (i) government taking the lead; (ii) improving building energy efficiency for both new and existing buildings because buildings consume $90 \%$ of the city's electricity usage; (iii) advising companies, institutions, and residents to make efficient energy choices when they procure electrical appliances and vehicles; and (iv) promoting energy saving practices and lifestyle for the people of Hong Kong. Hong Kong government, together with Hong Kong Green Building Council (HKGBC), acknowledges that 'green building' scheme (the practice of creating structures and processes that are more environmentally responsible and resource-efficient throughout a building's life cycle) needs to be energy efficient. By the time this report was released, there were approximately 900 building projects in Hong Kong that have been either registered or certified under the BEAM Plus assessment (Building Environmental Assessment Method) or its former system.

The BEAM Plus assessment is the Hong Kong's leading initiative to offer independent assessments of the performance of building sustainability. It was first established in Hong Kong in 1996 and revised over time with the latest being in 2012. The BEAM Plus New Building assessment scheme includes six aspects of a building project and BEAM Society Ltd. revises the assessment criteria from time to time in accordance with local and international best practices: (i) Site aspects; (ii) Energy use; (iii) Water use; (iv) Materials aspects; (v) Indoor environmental quality; and (vi) Innovations and additions. The BEAM Plus Interior assessment scheme was first introduced in 2013 and the BEAM Plus Neighborhood assessment scheme was first introduced in 2016.

Hong Kong government has taken the lead through showcasing several new public buildings and projects such as: (i) Zero Carbon Building (ZCB) that is $45 \%$ more energy efficient than current standard buildings because it runs on renewable energy (RE) sources; (ii) T-Park which is the city's first self-sustained sludge treatment facilities. It is a waste-to-energy plant. Surplus energy generated from this plant will be exported to the power grid for external use; and (iii) making full use of biogas from sewage treatment works to generate electricity by Drainage Services Department in 2013 and creating the first generator of hydropower plants by Water Services Department the same year.

Hong Kong government required all existing government buildings with floor area of more than $10,000 \mathrm{~m}^{2}$ to carry out regular carbon audit to track the reduction of greenhouse gas emission and to identify energy management opportunities and improve energy efficiency of 
buildings through a systematic review of the energy consuming equipment systems in a building.

\subsection{Hong Kong's Climate Action Plan 2030+ [10]}

The following literature is extracted from the report of 'Hong Kong's Climate Action Plan 2030+'. The report was introduced in January 2017 as a response to the COP-21 Paris Agreement. This document itemized the multiple co-benefits for Hong Kong to come up with this plan such as: (i) cleaner environment and better health; (ii) low carbon transport and more leisure spaces; (iii) richer biodiversity and more climate resilient; (iv) green lifestyles, green jobs, and happier people; (v) less waste and more sustainable; and (vi) efficient homes and productivity offices. China formally signed the Paris Agreement on 22 April 2016 and ratified on 3 September 2016. As a Special Administrative Region of China, Hong Kong has been proactively preparing its city to operationalize the Paris Agreement. Hong Kong's operational framework on climate change in setting targets with timelines, ensuring there are transparent metrics to track results, and for everyone to work together to achieve the decarbonizing goals that is also known as 4Ts-Timelines; Targets; Together; and Transparency. Hong Kong's goal is to reduce its carbon intensity by $65 \%$ to $70 \%$ by 2030 using 2005 as the base. The 4T partnership between government and private building sector is carried out according to the following five aspects: (i) collaboration with HKGBC and BEAM Society Limited to showcase green building; (ii) auditing and implementing energy management opportunities through retrofit; (iii) launching green procurement; (iv) encouraging extra performance building energy code for new buildings; and (v) retrocommissioning and retrofitting of government buildings.

Hong Kong plans to reduce its greenhouse gas emission per capita to less than 4.5 tonnes $\mathrm{Co}_{2} \mathrm{e}$ by 2020 and to further reduce it about 3.3 to 3.8 tonnes $\mathrm{CO}_{2} \mathrm{e}$. In future, the usage of coal-fired electricity generation will be phased down which not only helps to meet the new carbon intensity reduction target, but also gives significant air quality and public health benefits. Furthermore, Hong Kong will apply RE on a wider and larger scale in the immediate years ahead based on mature and commercially available technologies with the public sector taking the lead. Hong Kong also encourages the private sector to adopt RE through creating the condition that facilitates the private sector to adopt this approach.

\subsection{Vancouver's Greenest City 2020 Action Plan [11]}

The following literature is extracted from the City of Vancouver's 'Greenest City 2020 Action Plan' (GCAP) report. GCAP was first established as a result of the work of Mayor Gregor Robertson's Greenest City Action Team in 2009. At that time, more than 35,000 people from around the world contributed to the creation of GCAP including residents, city staff, and public organizations. Vancouver indicates four key ingredients in their GCAP: (i) Vision, (ii) Leadership, (iii) Action, and (iv) Partnerships. The plan is divided into 10 unique goals (each with a long-term [year 2050] goals and medium-term [year 2020] targets): (i) Green Economy, (ii) Climate Leadership, (iii) Green Buildings, (iv) Green Transportation, (v) Zero Waste, (vi) Access to Nature, (vii) Lighter Footprint, (viii) Clean Water, (ix) Clean Air, and (x) Local Food.

Vancouver's 'Green Economy' is growing more than twice as fast as traditional sectors by implementing the following four key strategies: (i) Economic development; (ii) Community economic development; (iii) Capacity building, education, and training; and (iv) Greening 
existing workplaces. To foster 'Climate Leadership', Vancouver targets to reduce community-based greenhouse gas emission by $33 \%$ from 2007 levels by the following key strategies: (i) Helping to bring new neighborhood-scale RE systems online; (ii) Supporting implementation of green buildings, green transportation, and zero-waste plans; (iii) Developing a climate change adaptation plan; and (iv) Supporting provincial climate and energy plans. In order to foster a city of 'green buildings', Vancouver targets to require all buildings constructed from 2020 onwards to be carbon neutral in operations through the following key strategies: (i) Regulation, (ii) Financing tools and incentives to green existing buildings, (iii) Capacity building, and (iv) Education and outreach programs to engage building occupants. Vancouver's plan under the 'Green Transportation' category is to make walking, cycling, and public transit to be the preferred transportation options for all ages and abilities.

Vancouver's goal for 'Zero Waste' is to reduce solid waste going to the landfills or incinerators by $50 \%$ from 2008 levels. In the area of 'Access to Nature', Vancouver targets to have all its residents live within a five-minute walk distance from a park, greenway, or other green space by 2020 and to plant 150,000 new trees by 2020. Vancouver's plan to promote 'Lighter Footprint' is through reducing its residents' ecological footprint by $33 \%$ over 2006 levels.

\subsection{Research Questions}

1. How the local governments in Hong Kong and Vancouver interact with their local GBCs in greening their cities?

2. What are the similarities and differences among the two cities' local governments and their GBCs in transforming the cities to become more sustainable?

3. What are the overall perspectives and visions of International green NGOs such as United Nations Environmental Program (UNEP) and the WGBC in transforming cities to become sustainable and to mitigate climate change?

\section{METHOD}

\subsection{Context}

Hong Kong is a Special Administrative Region of China with a population of 7.22 million in 2015. It has a land area of $1,104 \mathrm{~km}^{2}$, with Gross Domestic Product (GDP) of 272 billion USD. Hong Kong is considered to be a leader in the green building movement through government's policies that promote energy efficiency and environmentally sound practices. HKGBC works tirelessly to enhance their knowledge and presence in the international community for a sustainable built environment through their participation as an established member of the WGBC and sending a representative on its Board of Directors.

Hong Kong hosted the WGBC Congress in mid-October 2015 and the World Sustainable Built Environment Conference in early June 2017. Both events can be seen as Hong Kong's effort to accelerate the progress of green building movement in the city. The building sectors account for approximately $90 \%$ of total electricity consumption in Hong Kong. The introduction of a local BEAM Plus green building rating system has successfully encouraged the growth of sustainable design and construction within the city. The city of Hong Kong aims to reduce its carbon intensity by $50 \%$ to $60 \%$ levels by 2020 [12].

Vancouver has 600,000 people in 2015 . It has a land area of $114 \mathrm{~km}^{2}$, with GDP of 101.2 billion USD. Vancouver's GCAP is intended to address the city's environmental 
challenges through measurable and attainable targets. The plan was enacted in 2011 with the aim to make Vancouver the greenest city in the world by 2020. Vancouver has taken on four high-priority actions for greening city operations that will aid in meeting targets established in the GCAP. All new municipal facilities are required to be built to achieve LEED Gold certification. Existing facilities will also be upgraded to be more energy efficient. In other areas of city's operation, Vancouver achieved a $70 \%$ average waste recycling rate for city buildings in 2013; City Hall achieved $85 \%$ diversion rate. The city of Vancouver aims to achieve a $33 \%$ reduction in $\mathrm{CO}_{2}$ emission by 2020 [12]

\subsection{Participants}

Semi-structured interviews were conducted with a total of nine professionals of experts in the sustainable movement in the built and environment field in Vancouver, Hong Kong, and International to represent leaders' voices and to foresee the direction of the green buildings/ sustainable cities movement in the future (see Table 1).

\subsection{Procedure}

Ethical clearance was obtained and Letters of Invitation of Participation in this study were issued prior to scheduling face-to-face or skype interviews. Semi-structure interviews were chosen to elicit a deep and nuanced understanding of the stakeholders' views about sustainable cities and the roles of governments and GBCs to promote it in the past, at present, and the projection for future planning. The interviews lasted between 60 to 120 minutes. All interviews other than Prof. John Ng's (to meet his request for no audio-tape) were audiotaped and transcribed before they were coded according to the common themes.

Table 1: Interview participants.

\begin{tabular}{lll}
\hline Represent & Name & Position \\
\hline International & Dr. Stefanos Fotiou & $\begin{array}{l}\text { Head of Cities and Lifestyles, UNEP (2015); Chief } \\
\text { of Division, Environment \& Development Divi- } \\
\text { sion, United Nations ESCAP (2016-present) } \\
\text { Chairman of World Green Building Council } \\
\text { (2016-present) } \\
\text { Director of World Green Building Council } \\
\text { (2015-present) }\end{array}$ \\
Hong Kong & Mr. Conrad Wong & $\begin{array}{l}\text { Under Secretary for the Environment of Hong } \\
\text { Kong SAR (2012-2017) }\end{array}$ \\
& Sr Wong Bay & $\begin{array}{l}\text { Hong Kong Green Building Council Chairman } \\
\text { (2017-present) } \\
\text { Hong Kong Green Building Council Chairman } \\
\text { (2015-2016) }\end{array}$ \\
& Prof. Cheung Hau Wain Ng & $\begin{array}{l}\text { Chairperson of BEAM Society Ltd. (2016-present) } \\
\text { City Councilor of Vancouver (2016-present) } \\
\text { President and CEO of Canada Green Building } \\
\text { Council (2005-present) }\end{array}$ \\
\hline
\end{tabular}




\section{RESULTS}

Comparative perspectives on various topics to understand the cities' sustainable goals are listed below.

Table 2: Participants' perspectives on climate mitigation.

International

UN-ESCAP Focusing on 'Climate Change Finance' to boost investment on clean-energy and any other investment related to climate mitigation projects, promoting Eco-Tourism with its correct understanding.

WGBC Introducing 'Advancing Net Zero' projects with the goals for buildings and neighborhoods to achieve net zero projects by 2050.

Speaking with the users' language to educate them about green buildings (e.g. 'Better Places for People' campaign).

Hong Kong

Hong Kong Government Government prioritizes on climate change since it involves a lot of activities in HK including green buildings, reduction of carbon emission, saving energy, etc. HK comes under China and since China ratified the COP-21 agreement, HK must follow the timetable set by China, which follows the UNFCCC's time table. However, HK looks at Paris Agreement itself and comes up with its own target because under the 'one country two systems' administration, China national policy does not bind Hong Kong.

HKGBC and BEAM BEAM Society Ltd. enhances the rating tools for green buildSociety Ltd. ings such as the addition of BEAM Plus from New Building (NB) to Neighborhood Development (ND); from Building Interior (BI) to Existing Buildings (EB). EB is a big problem in HK since over $90 \%$ of the building stocks are existing buildings. HKGBC helps the government by giving idea of HK 2030, which further developed by the HK Government.

Vancouver

Vancouver Government Vancouver has a head start when it comes to climate readiness as the first city to adopt climate change starting from 1990s. Comes up with the GCAP 2020 where each goal has a strategy and policy associated with them. Vancouver is also the first city in North America that comes up with a renewable energy plan for city's strategy.

Canada GBC Canada Green Building Council promotes various green build(CaGBC) ing rating tools (LEED Canada) with various improvements and continuing to develop the certification for LEED v.4. 
Table 3: Participants' perspectives on the role of local government and GBC.

International

UN-ESCAP The national government should maintain their own framework for building codes, while GBCs can take the lead to mainstream the green buildings into building codes.

WGBC Green building movement cannot be successful without government's involvement. The first thing for those who want to build a $\mathrm{GBC}$, it is always good to engage the government from Day 1.

Hong Kong

Hong Kong Government Government appointed Secretary for the Environment to chair a steering committee to propagate green building movement in 2013 and set all government buildings to be green buildings. Government thinks that HKGBC plays an important role and has close relationship with HKGBC where government sets the policy and HKGBC advocates. Government sends people to attend GBCs events.

HKGBC and BEAM HKGBC supports the government as they determine the policy. Society Ltd. Government provides the overarching policy and gives direction while HKGBC tries to implement. They encourage the construction of new green buildings, retrofitting existing buildings to maximize energy savings. HKGBC gives recognitions to building owners who take the initiative such as giving the BEAM Plus labels. There has been a collaboration even with Education Bureau with HKGBC.

Vancouver

Vancouver Government Vancouver has the fastest growing economy, the most resilience, and the strongest. The focus of what diversifying the economy is green jobs. People move to Vancouver because of green jobs. Many new opportunities on jobs related to green buildings since the city has the largest green building clusters in the West Coast of North America. The city also tries to be zero waste and to reuse waste for construction materials, which opens new job markets for the material waster recovery plan. The City of Vancouver and $\mathrm{Ca}-\mathrm{GBC}$ has very close relationship and they often interact.

Canada GBC (CaGBC)
$\mathrm{Ca}-\mathrm{GBC}$ has been working with the city for the last three years on the green building strategies. Government is looking at net zero buildings for their own building stock and CaGBC is developing net Zero Carbon Building standard for Canada. CaGBC advocates Government (from city government to federal government). They do not make policy but suggest policy. CaGBC moves faster than government. They give advice and try to push the government forward but CaGBC does not wait for the government to implement their programs due to the uncertainty whether government will make it happen or not. 
Table 4: Participants' perspectives on disseminating green visions.

International

UN-ESCAP Partnering with government and NPOs such as universities while providing technical support and capacity building for other developing countries.

WGBC It is critical to understand the contexts (geographical, socio, and environmental). To share about the basic business case for green buildings that will be beneficial in the long-term. WGBC cannot regulate local GBCs. WGBC inspires local GBCs to be more progressive in green building movement.

Hong Kong

Hong Kong Government Creating the document for climate change readiness that is effective and measureable. Doing a lot of adaptation from COP21 Agreement. Interacting and seeking advices from local green groups, HKGBC, and industry.

HKGBC and BEAM Presenting business case about green buildings, educating the Society Ltd. $\quad$ public that green buildings are good for health and wellbeing, providing them with practical measure to show the benefit of upgrading their buildings to meet the environmental performance. Issuing guidebooks for shopping malls, offices, and green schools.

Vancouver

Vancouver Government Vancouver has very few legislative tools, but they inspire the general public so that they can be involved and support the GCAP 2020. The city government outreached to all kinds of social groups (universities, business organizations, labor unions, faith groups, new immigrants, and so forth).

Canada GBC CaGBC also made up by industries so they work with the real (CaGBC) estate industry to bring up changes particularly on climate, waste, and water.

Table 5: Participants' perspectives on challenges ahead.

International

UN-ESCAP The need for effective communication to the governments and to increase capacity of the government institutions.

WGBC The difficulties to educate the public and to raise funding to support more resources into this type of education.

Hong Kong

Hong Kong Government The bureaucratic administration system of the government in Hong Kong may hinder the progress of legislation sometimes. Bureaucracy exists within the governmental structure. It takes government officials some skills to go around and get things done. 
Table 5: (Continued)

\begin{tabular}{ll}
\hline HKGBC and BEAM & The challenge is that we only cover a small group of people \\
Society Ltd. & while our vision is for everybody in the society to respect green, \\
& to practice green, and to change their behaviors to become more \\
& sustainable.
\end{tabular}

Vancouver

Vancouver Government It is difficult to convince the people about climate. It is also tough to reconcile the dual personality as being proud for the climate leadership in Vancouver but also wanting what other North American cities wanted.

Canada GBC

In Canada, people do not like to be told what to do. It is im$(\mathrm{CaGBC})$ portant to take a soft approach and it is mainly through public education.

Table 6: Participants' perspectives on motivation strategies to countries/general public.

International

UN-ESCAP Showcasing to the countries about the benefits of adopting the courses for sustainable development.

WGBC Educating people about the importance to be climate ready should start from the early years.

Hong Kong

Hong Kong Government Having a close work relationship with Construction Industry Council and HKGBC and to frequently participate in their public activities to show the general public about government's support. Government makes policy, CIC and HKGBC advocate.

HKGBC and BEAM Inviting the public to visit Zero Carbon Building to see how Society Ltd. the architecture was designed and operated that gives education about green construction. Through education and publicity that green buildings can be promoted.

Vancouver

Vancouver Government $\quad$ To reach out and engage the general public for decision making. People of Vancouver are very self-motivated and they actively contribute ideas. The City of Vancouver also has external advisory teams consist of civil society groups from universities, business organizations, labor unions, etc. for decision-making engagement.

Canada GBC $(\mathrm{CaGBC})$ Since averaged Canadians do not like to be told, the city government has done a lot to educate the public by making people come to the realization themselves alone (ex/not wasting energy). 
Table 7: Participants' perspectives on successful stories, current actions, and suggestions for further improvement.

International

UN-ESCAP Making the best use of technology that can give better solution for sustainable infrastructure and sustainable housing at the city level. Thinking smartly about waste management. Promoting investment in sustainable infrastructure. Establishing policy that can push for sustainable behaviors and green investment.

WGBC It is critical to think about the 'Funding Model' in the earliest stage of forming GBC.

Developing measurement tools to look at how successful GBCs such as: (i) the number of green buildings and (ii) the number of green professionals in a country.

Hong Kong

Hong Kong Government Creating a campaign similar to Civic Exchange's 'Fair Wind Charter', but can name it as 'Fair Building Charter'.

HKGBC and BEAM Society Ltd. We should focus for the Intended Nationally Determined Contributions (INDC) reports in 2020. Green building is not just about building but a culture. And it is very difficult to change a culture. We can achieve Net-Zero through carbon trading, energy transparency, and giving incentive to upgrade existing buildings.

Vancouver

Vancouver Government Many important things matter such as leadership, good plans, high level goals, and big data. The idea of forcing others to do something does not work because people act based on self-motivation. Citizens are very self-motivated to advocate government's policies. This is encouraging.

Canada GBC The City of Vancouver has an advantage since the weather is a $(\mathrm{CaGBC})$ mild-climate; all electricity in Vancouver is hydroelectric (with very low carbon intensity since they get it from water).

\section{DISCUSSIONS}

\subsection{Vancouver Has a Head Start in Climate Mitigation, While Hong Kong Has Ambitious Plans}

Vancouver has competitive advantage in climate mitigation due to its head start in this movement. According to City Councilor Andrea Reimer, Vancouver started in the early 1990s in recognizing the impact brought by climate change and became the first city to develop a mitigation plan. Hong Kong, on the other hand, moved on faster pace in the area of climate change mitigation dated back in 2007. According to Ir. Conrad Wong, one of the founding Directors of HKGBC and currently Director of WGBC, many construction professionals recognized the need to form a GBC in Hong Kong but there was no consolidated effort. 
Mrs. Carrie Lam, who was then the Secretary for Development, participated at the World Sustainable Building Conference in Melbourne in 2008 and came back to Hong Kong with full support to the establishment of HKGBC in 2009. Since then, Hong Kong has been walking on ambitious footsteps with its green building plan driven by the government and advocating by HKGBC. Furthermore, Hong Kong came up with detail plans in the two documents: 'Energy Saving Plan for Hong Kong's Built Environment 2015-2025+' and 'Hong Kong's Climate Action Plan 2030+'. Hong Kong's climate change mitigation plans are meticulous and ambitious, but concentrating only in a few areas such as the built environment, transport, and energy. Hong Kong is fast in adapting to clean energy sources with new projects such as facilitating the wind projects in South West Lamma and South East Ninepin, installing new PVs to capture solar energy, developing a new hydropower plant at Tuen Mun Water Treatment Works, and launching the new T-Park.

Vancouver, on the other hand, came up with its comprehensive 'Greenest City 2020 Action Plan' with 10 items coverage, but the plans under each goal are not too details. Andrea Reimer and President and CEO of CaGBC, Thomas Mueller, both talked about Vancouver's clean energy sources from hydroelectricity generation that encompasses $97 \%$ of energy used in the city.

\subsection{Supports from Government Leaders to the Proactive Green Movements of GBCs}

Governments support to green building movement and their close collaboration with GBCs consider to be a facilitating factor given that the GBCs are also active in their work in greening the cities. Interestingly, Hong Kong and Vancouver are very similar in these areas. Hong Kong's current Chief Executive, Mrs. Carrie Lam, is known to be the driving force behind the establishment of HKGBC. Vancouver's Mayor Gregor Robertson was the co-committee chair for the Greenest City Action Team that initially developed the GCAP 2020. Furthermore, interview data confirmed the close relationship among local governments with their GBCs leaders in both cities. It is understood that governments are responsible for developing policies that support the green building movement, while GBCs advocate the green building movement among practitioners, academics, and general public. It is apparently the shared vision and mutual collaboration of the local governments and GBCs that speed up the transformation of both cities to become more sustainable. Both governments came up with the plans and goals to decarbonize the cities. CaGBC assists Vancouver government to develop 'Net Zero Carbon Building Standard' for Canada with the focus on large high-residential buildings. While, according to the present Chairman of HKGBC, Sr. Wong Bay, HKGBC always asks support and questions to the government to ensure positive communication while listening to their advice, appreciate their position, respect their difficulties, and find out a win-win solution for all parties. As a result, there are many new green buildings constructed in both cities in the recent years. Examples in Hong Kong: (i) Zero Carbon Building for Exhibition Center; (ii) 'T-Park' for Waste-to-Energy Plant; (iii) Hysan Place for Shopping Mall; (iv) Holiday Inn Soho for Hotel; and many others. Examples in Vancouver: (i) Winter Olympic Village for Residential Complex, (ii) Van Dusen for Botanical Garden, (iii) Center for Interactive Research on Sustainability (CIRS) for University Building, (iv) Telus Garden for Commercial, and many others.

\subsection{Capacity Building in Hong Kong and Vancouver}

The two differing approaches in the area of capacity building in both cities can be attributed to the different cultural contexts. Hong Kong green movement's style is hierarchical with 
government heavily leading the initiative and closely monitoring the movement. HKGBC plays an important role in transforming the city to become more sustainable because they spread government's larger vision to the general public (other institutions, private corporations, and students) through various 'green' initiatives such as workshop, training, conferences, and competition. HKGBC also tries to quickly learn from many international experts and to position Hong Kong as a hub for the green building movement by hosting WGBC 2015 and WSBE 2017. These two international events were used as platforms for many international green experts to visit Hong Kong and to share their expertise with each other. Hong Kong government and HKGBC leaders' close collaboration has been proven to be effective in speeding up the process of capacity building for professionals (academics, private developers, building practitioners such as architects, engineers, and other consultants) even though they admitted their efforts have not really covered the majority of Hong Kong urban dwellers to embrace the green movement in the city. Vancouver's green movement style is more flat that the government engaged the public, sought and consulted their opinions, prior to the final decisions in coming up with 10 goals for GCAP. Councilor Andrea Reimer and CEO of CaGBC Thomas Mueller both stated that urban dwellers in Vancouver do not like to be told what to do. Therefore, for the green movement at a city level what leaders do is to inspire the residents to believe in the GCAP goals and involving them to come up with the strategies to achieve the goals while the leaders act to facilitate the green movement. The large different of both cities' population can also be attributed to the different styles because it is more difficult to have a flat capacity building to spread green movement in a large population over 7 million residents in Hong Kong compared to about 600,000 residents in Vancouver.

\subsection{The UN and WGBC Overall Visions on Sustainable Cities}

The UN and WGBC have wider perspectives when it comes to sustainable cities. Dr. Stefanos Fotiou, previously the Head of Cities and Lifestyles for UNEP and currently Director of Environment and Development of UN-ESCAP, stated that there has been an increased request from the member states of various countries asking for support on mitigating climate change issue. Therefore, one of his team's main tasks is to build the capacity of finance institutions to provide climate finance not only to the public but also to the private sector. Similarly, Ir. Conrad Wong, Director of WGBC, discussed the criticality of coming up with Funding Model for GBC to thrive. Since WGBC and local GBCs are NGOs, without solid funding models, then it will be difficult to carry on various projects under the organizations. Mr. Tai Lee Siang, Chairman of WGBC, shared about the organization's latest project called 'Advancing Net Zero' that needs to be defined in a universal language of what is net zero, but also needs to be contextualized according to each country's situation. Mr. Tai Lee Siang's version of net zero is about minimizing emission and reducing energy consumption for buildings and also for districts/neighborhoods. Dr. Stefanos Fotio and Mr. Tai Lee Siang both believe it is critical for local governments to adopt green building not only as optional, but integrate them in the cities' building codes because they believe this approach is good for the environment and for the wellbeing of people.

\section{LIMITATIONS}

This research contributed to the understanding of sustainable cities and the process of achieving such status. We acknowledge that our research might be limited to time and financial constraint that we only managed to interviews the main leaders behind this green movement whereas it will be interesting to find out more from the general public's opinions about the 
process and success of both cities in achieving their goals. This research is significant by providing empirical data of comparative case studies of two prominent cosmopolitan cities with ambitious goals in greening their cities as case studies.

\section{CONCLUSION}

Cities landscapes are dynamic that they change rapidly according to various factors and there is not a set of blue print of greening a city as each place has its own unique approach. Cities have many complexes issues that need to be tackle holistically and thoughtfully. The green movements in both cities bring positive changes not only to mitigate climate change, but also to enhance the livability in the city that benefit the urban dwellers' health and wellbeing. Hong Kong and Vancouver, undeniably are good models of cities transformation that showcase good leadership from their governments and GBCs leaders to take initiative in greening their cities. Interestingly even though Hong Kong and Vancouver are separated miles apart and have distinct cultural values, they are similar when it comes to the ambition in greening its cities, the close relationship among the local governments with their GBCs, and the eagerness to enhance the wellbeing of its urban residences through decarbonizing efforts. Both governments take the lead in promoting green buildings movement with Vancouver municipalities required all of its new facilities to be built achieving LEED Gold certification and with Hong Kong government implemented a BEAM Plus certification requirement for developers seeking additional project floor area. Green building labels in both cities, however, are still optional with providing positive incentives to encourage more developers to take this route. Meanwhile, the overall visions from the UN and WGBC representatives showcase the need for green building movement to be taken seriously and not only as good option for the industry, but they hope that one day green building design can be implemented under a mandatory policy. This research is significant in describing the efforts of both cities and the process of cities' transformation through discussing various strategies that the cities take in enhancing their status in becoming sustainable cities. The results of this research can be utilized as learning tool for other cities that might consider in greening their cities or in achieving the sustainable cities status. Each city is unique with individual context and groups of urban dwellers. Nevertheless, if the cities leaders take the initiative and actively educate themselves in the area of sustainable cities, the goal in preserving our planet earth to be a sustainable place to live can soon be realized.

\section{REFERENCES}

[1] United Nations Department of Economic and Social Affairs. Available at: https://www. un.org/development/desa/en. (accessed 12 April 2017).

[2] Pearson, L., Newton, P. \& Roberts P., (eds.). Resilient Sustainable Cities. Routledge, New York, NY, p. 19, 2014.

[3] UN-Habitat. Available at: https://unhabitat.org. (accessed 12 April 2017).

[4] Hojer, M. \& Wangel, J., Smart Sustainable Cities - Definition and Challenges. Online publication at ResearchGate. Available at: https://researchgate.net/publication/265594929. (accessed 15 September 2016).

[5] Pearson, L., Newton, P. \& Roberts P., (eds.). Resilient Sustainable Cities: Routledge, New York, NY, p. 19, 2014.

[6] Pearson, L., Newton, P. \& Roberts P., (eds.). Resilient Sustainable Cities: Routledge, New York, NY, p. 7, 2014.

[7] Pearson, L., Newton, P. \& Roberts P., (eds.). Resilient Sustainable Cities: Routledge, New York, NY, pp. 7-8, 2014. 
[8] Core Writing Team, Pachauri, R.K. \& Reisinger, A. (eds.). Climate Change 2007: Synthesis Report. Available at: http://www.ipcc.ch/publications_and_data/publications_ ipcc_fourth_assessment_report_synthesis_report.htm. (accessed 7 May 2017).

[9] Environment Bureau of the Government of Hong Kong SAR. Energy Saving Plan for Hong Kong's Built Environment 2015-2025+. Available at: http://www.enb.gov.hk/ sites/default/files/pdf/EnergySavingPlanEn.pdf. (accessed 10 May 2017).

[10] Environment Bureau of the Government of Hong Kong SAR. Hong Kong's Climate Action Plan 2030+. Available at: http://www.enb.gov.hk/sites/default/files/pdf/ClimateActionPlanEng.pdf. (accessed 10 May 2017).

[11] City of Vancouver. Greenest City 2020 Action Plan. Available at: http://vancouver.ca/ files/cov/Greenest-city-action-plan.pdf. (accessed 29 August 2016).

[12] C40 Cities Climate Leadership Group, U.S. Green Building Council \& World Green Building Council. Green Building City Market Briefs. Available at: http://www.c40.org/ blog_posts/c40-usgbc-release-green-building-city-market-briefs. (accessed 22 May 2016). 